\title{
Technical Note: Community of bacteria attached on the PVDF MF membrane surface fouled from drinking water treatment, in Seoul, Korea
}

\author{
K. Chon ${ }^{1}$, K. Chon ${ }^{1}$, J.-S. Chang ${ }^{2}$, H. Oh ${ }^{3}$, E. Lee ${ }^{3}$, and J. Cho ${ }^{1}$ \\ ${ }^{1}$ NOM Lab., Department of Environmental Science and Engineering, Gwangju Institute of Science and \\ Technology (GIST), 1 Oryong-dong, Buk-gu, Gwangju 500-712, Korea \\ ${ }^{2}$ Department of Biological and Chemical Engineering, Yianbian University of Science and Technology \\ (YUST), ChaoYang Street, Yianji, Jilin Province, 133-000, China \\ ${ }^{3}$ Environmental Technology Research Team, DAEWOO E\&C, 60 Songjuk-dong Jangan-gu Suwon city \\ Gyeonggi-do, Korea
}

Received: 31 January 2009 - Published in Drink. Water Eng. Sci. Discuss.: 2 March 2009

Revised: 25 June 2009 - Accepted: 30 June 2009 - Published: 6 August 2009

\begin{abstract}
Alpha, beta, and gamma proteobacteria comprise approximately 68,16 , and $7 \%$ of all identified bacteria. In this study, bacterial communities that had fouled polyvinylidene fluoride microfiltration membranes, which are used for drinking water treatment, over an 18 month period were analyzed using the $16 \mathrm{~s}$ rRNA gene clone library method. The alpha, beta, and gamma proteobacteria were composed of mainly Bradyrhizobium and Rhodopseudomonas, Ralstonia, and Legionella, respectively. The presence of a relatively high amount of alpha proteobacteria was due to the oligotrophic condition of the drinking water source, the Han River, tested in this specific case study. The second most prominent bacteria community was the beta proteobacteria, which are typically found in a freshwater environment. This finding supports the notion that the drinking water source was relatively clean. Analyses of the organic foulants indicated that they were most likely from extra cellular polymers and/or cell fractured chemicals from bacteria or micro-organisms, as identified using organic characterizing tools, including 3-D fluorescence excitation-emission matrix and Fourier transform IR analyses.
\end{abstract}

\section{Introduction}

Relatively new attempts in the characterization of fouling have been conducted in the areas of biofouling and microbial extra-cellular polymeric substances (EPS). The development of such characterization techniques are especially important for the identification of microbial communities in fouled membrane, which may provide a better understanding of biofouling formation mechanisms including microorganisms and EPS. Bacterial community structure analyses have recently been performed for membranes that were fouled during wastewater and effluent treatment (Ivnitsky et al., 2007; Miura et al., 2007; Pang and Liu, 2007; Chen et al., 2004). The bacterial community was identified using both polymerase chain reaction (PCR)-denaturing gradient

Correspondence to: J. Cho

(jwcho@gist.ac.kr) gel electrophoresis (DGGE) and 16S rDNA gene clone library methods, in conjunction with providing phylogenetic tree information. Specific functional genes, such as the denitrifying nirK gene, were also detected in biofilms formed on biofouled membrane (Pang and Liu, 2007). Even with different trends, $\alpha$-, $\beta$-, and $\gamma$-proteobacteria were most dominant in fouled membranes that were used to treat both wastewater and advanced treated effluent, with other classes and orders also being identified to lesser extents. Compared to studies that have examined membranes fouled during wastewater treatment, bacterial community structural analysis relating to drinking water treatment has rarely been studied; bacterial community identification was conducted with a drinking water supply system and biofilms formed in a drinking water distribution system (Eichler et al., 2006; Kalmbach et al., 2000). In this case study, Aquabacterium commune, which is in the subclass of $\beta$-proteobacteria, was found to be the dominant bacteria using the rRNA targeted probe method. 
Foulants from membranes fouled during drinking water treatment have been extensively characterized, mostly using chemical characterizing tools. In these studies, micro-organisms originated macromolecules, including colloidal organic matters (cell-wall fractured and relatively hydrophilic $\mathrm{N}$-acetyl amino sugars), were found to be the major source of biofouling (Leenheer et al., 2000; Kwon et al., 2005). However, the direct identification of the type of bacteria that accumulated on the fouled membranes used for drinking water treatment have been very rare; thus, this was examined in this study.

\section{Methods and materials}

\subsection{Bacteria community analysis}

Microbial biomass was collected from the polyvinylidene fluoride (PVDF) MF membrane surface using mechanical beating with a bead beater. Genomic DNA was extracted using the AccuPrep Genomic DNA extraction kit (k-3032, Bioneer, Korea), according to the manufacturer's instructions. Polymerase chain reaction (PCR) amplification for 16S rRNA was performed using universal primers 9F (5'GAG TTT GAT CCT GGC TCA G-3') and 1512R (5'ACG GCT ACC TTG TTA CGA CTT-3') (Weisburg et al., 1991). The PCR mixture included PCR premix (AccuPower PCR PreMix kit, Bioneer, Korea), $1 \mu \mathrm{L}$ of 10 pmole of each primer, and $30 \mathrm{ng}$ of template DNA. The reaction conditions were $94^{\circ}$ for $10 \mathrm{~min}$, followed by 34 cycles at $94^{\circ}$ for $30 \mathrm{~s}, 55^{\circ}$ for $30 \mathrm{~s}$, and $72^{\circ}$ for $1 \mathrm{~min}$, and a final extension step at $72^{\circ}$ for $10 \mathrm{~min}$. The amplicons were purified using the AccuPrep PCR purification kit (k-3034, Bioneer, Korea). The purified PCR products were ligated into the yT\&A cloning vector (RBC, Twain) and transformed into HITDH5 $\alpha$ (RH617, RBC) cells. Transformants were selected on Luria-Bertani agar plates containing ampicilin $(70 \mu \mathrm{g} / \mathrm{ml})$, $20 \mu \mathrm{L}$ of X-gal $(40 \mathrm{mg} / \mathrm{ml})$, and $50 \mu \mathrm{L}$ of IPTG $(200 \mathrm{mM})$. A single white colony having the recombinant plasmids was inoculated into $1 \mathrm{ml} \mathrm{LB}$ broth with ampicilin $(70 \mu \mathrm{g} / \mathrm{ml})$, and incubated at $37^{\circ}$ for $12-14 \mathrm{~h}$. The plasmid DNA was then extracted and purified using the AccuPrep plasmid extraction kit (Bioneer, Korea), according to the manufacturer's instructions. Clones were then sequenced using an ABI 3730xl automated DNA analyzer (Applied Biosystems, Foster City, $\mathrm{CA})$ at Xenotech (Daejeon, Korea). Sequences were analyzed using the BLAST database (www.ncbi.nlm.nih.gov). Sequence alignments of those selected clones and closely related bacterial species were performed using the Clustal W version 1.7 program (Thomson et al., 1997) available in the BioEdit software package (Hall, 1999). Phylogenetic analyses of cloned the nucleotide sequence were conducted using MEGA version 3.1 (Kumar et al., 2004). The tree was constructed from a matrix of pair-wise genetic distances by the neighbor-joining method. The $16 \mathrm{~S}$ rDNA sequences reported

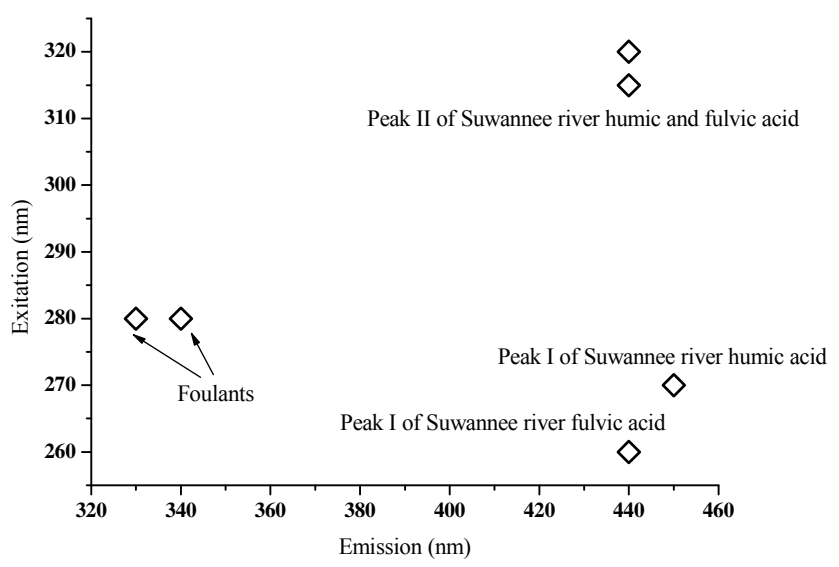

(a) Depicts of excitation and emission of peaks from 3-D fluorescence spectrophotometer.

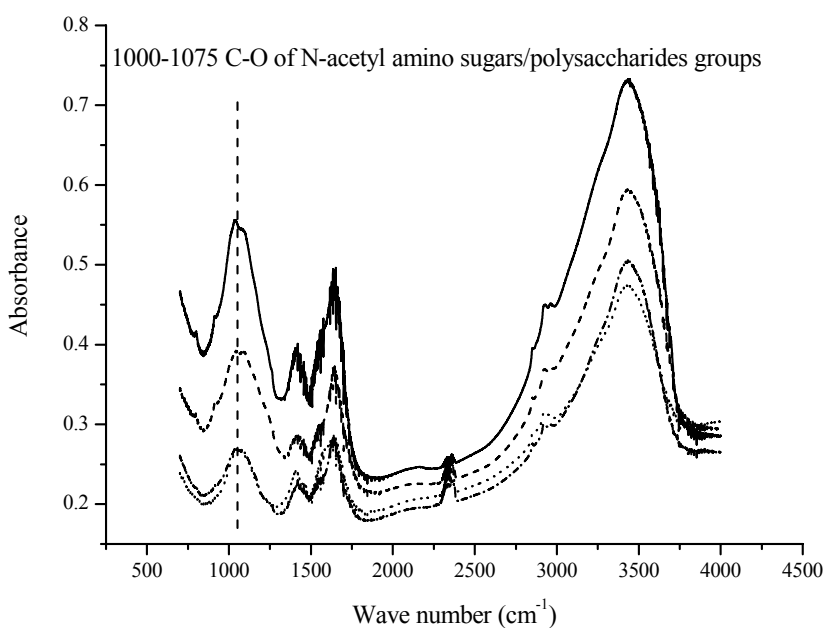

(b) FTIR spectra of the membrane foulants.

Figure 1. Foulants characterization.

here have been deposited in GenBank under the accession numbers FJ572662 to FJ572674.

\subsection{Organic foulants characterization}

The major components and complexity of organic foulants were identified using fluorescence spectrophotometer (F-2500, Hitachi, Japan), which provided 3-D fluorescence excitation emission spectra. Specific functional groups of various samples were confirmed using Fourier transform infrared (FTIR) spectrometer (FT/IR-460 plus, Jasco, Japan). A freeze dryer (Ilshin, Korea) was used to dessicate the water samples, and the IR spectrum was acquired with the $\mathrm{KBr}$ pellet (Pike, USA). Images of fouled membranes were obtained using field emission-scanning electron microscopy (FE-SEM) (Hitachi S-4700, Japan), after pretreatment with $5 \sim 6 \mathrm{~nm}$ Pt layering, using an Ion Sputter (Hitachi E-1030, Japan). 

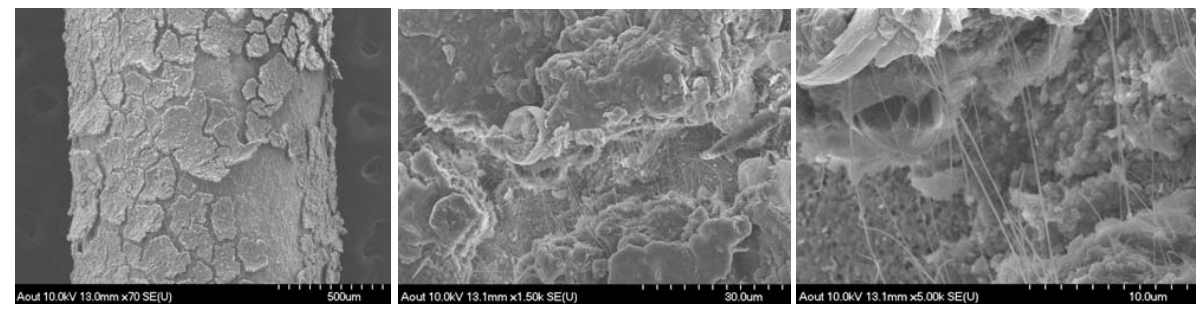

Figure 2. SEM images of fouled MF membranes $(\times 70, \times 1500, \times 5000)$.

Table 1. Summary of major bacteria from 120 colonies identified for the fouled MF membrane, as measured using the clone library method.

\begin{tabular}{|c|c|c|}
\hline $\begin{array}{l}\text { Phyogentic } \\
\text { group }\end{array}$ & $\begin{array}{l}\text { Major found } \\
\text { bacteria }\end{array}$ & $\begin{array}{l}\text { Occupying } \\
\text { percentage for } \\
120 \text { colonies }(\%)\end{array}$ \\
\hline$\alpha$-proteobacteria & $\begin{array}{l}\text { Bradyrhizobium sp., } \\
\text { Rhodopseudomonas sp. } \\
\text { and Afipia sp. }\end{array}$ & 68 \\
\hline$\beta$-proteobacteria & Ralstoina sp. & 16 \\
\hline$\gamma$-proteobacteria & Legionella sp. & 7 \\
\hline Planctomycetes & Planctomyces sp. & 7 \\
\hline
\end{tabular}

\section{Results and discussion}

Excitation and emission peaks measured from 3-D fluorescence spectra with chemically desorbed foulants using both $0.1 \mathrm{~N} \mathrm{NaOH}$ and $0.1 \mathrm{~N} \mathrm{HCl}$ provided information on the peaks that were different from those of humic substances obtained from the Suwannee river humic and fulvic acids (from International Humic Substance Society), and similar to those of protein-like substances (Fig. 1a) (Lee et al., 2006). FTIR peaks around $\sim 1000 \mathrm{~cm}^{-1}$, which corresponded to polysaccharides/cell fractured $\mathrm{N}$-acetyl amino sugar groups, were identified, as shown in Fig. 1b (Leenheer et al., 2000; Kwon et al., 2005). Along with these peaks, sticky materials, presumably EPS, were found through FE-SEM imaging (Fig. 2). Based on these three observations, it was hypothesized that the biofouling on the fouled membrane and related foulants originated from the presence of a substantial amount of micro-organisms on the membrane.

A 16S rDNA clone library was constructed for the fouled MF membrane. Phylogenetic analyses of 120 randomly selected clones revealed 15 operational taxonomic units (OTUs) assigned to various bacterial divisions, as listed in Tables 1 and 2. Phylogenetic analysis (Table 1 and Fig. 3) indicated that the Proteobacteria dominated on the membrane surface, where the $\alpha$-proteobacteria subdivision was the largest bacterial group (68\% of total clones) and the $\beta$-proteobacteria subdivision was the second largest bacte-
Table 2. Phylogentic distribution of identified bacteria from the fouled MF membrane.

\begin{tabular}{|c|c|c|c|}
\hline $\begin{array}{l}\text { Sequence type } \\
\text { (and percentage) } \\
\text { of total clones }\end{array}$ & $\begin{array}{l}\text { Phylogentic } \\
\text { group }\end{array}$ & $\begin{array}{l}\text { Most closely } \\
\text { related bacteria }\end{array}$ & $\begin{array}{l}\text { Simi- } \\
\text { larity } \\
(\%)\end{array}$ \\
\hline Clone $2(35.6 \%)$ & $\alpha$-proteobacteria & Bradyrhizobium sp. & $98-99$ \\
\hline Clone $148(17.8 \%)$ & $\alpha$-proteobacteria & Rhodopseudomonas sp. & 99 \\
\hline $\begin{array}{l}\text { Clones } 37(11.9 \%) \text {, } \\
\text { and } 142(0.8 \%)\end{array}$ & $\alpha$-proteobacteria & Afipia sp. & 98-99 \\
\hline Clone $147(0.8 \%)$ & $\alpha$-proteobacteria & Xanthobacter sp. & 99 \\
\hline Clone $75(0.8 \%)$ & $\alpha$-proteobacteria & Agrobacterium sp. & 99 \\
\hline Clones $87(11.9 \%)$ & $\beta$-proteobacteria & Ralstoina sp. & $98-99$ \\
\hline Clone $133(1.7 \%)$ & $\beta$-proteobacteria & Alcaligenes sp. & 99 \\
\hline Clones $117(1.7 \%)$ & $\beta$-proteobacteria & Curvibacter sp. & 96 \\
\hline Clone $135(0.8 \%)$ & $\beta$-proteobacteria & Janthinobacterium sp. & 98 \\
\hline Clone $40(6.8 \%)$ & $\gamma$-proteobacteria & Legionella $\mathrm{sp}$. & $94-96$ \\
\hline Clone $38(0.8 \%)$ & Bacteroidetes & Marinicola seohaensis & 88 \\
\hline Clone $21(0.8 \%)$ & High $\mathrm{G}+\mathrm{C}$ & Arthrobacter sp. & 99 \\
\hline Clone $23(0.8 \%)$ & High $\mathrm{G}+\mathrm{C}$ & Environmental clones & 96 \\
\hline Clone $26(6.8 \%)$ & Planctomycetes & Planctomyces sp. & 94 \\
\hline
\end{tabular}

rial group (16\% of total clones) found in the samples. The majority of the $\alpha$-proteobacterial OTUs were primarily affiliated with Bradyrhizobium sp., Rhodopseudomonas sp. and Afipia sp. The remaining clones in this group were closely related to Xanthobacter sp. and Agrobacterium sp. In the $\beta$-proteobacteria, the most dominant OTU (11.8\% of total clones) was closely related to Ralstoina sp., while the other 3 OTUs were closely related to Alcaligenes sp., Curvibacter sp. and Janthinobacterium sp.

The MF sample also contained 5OTUs from the $\gamma$-proteobacteria, the Planctomycetes group, the grampositive high $\mathrm{G}+\mathrm{C}$ group and Bacteroidetes group. In the $\gamma$-proteobacteria group, clone 40 (6.8\% of total clones) was closely related to Legionella sp. In the Planctomycetes group, clone 26 (6.8\% of total clones) was closely related to Planctomycetes sp. In the high $\mathrm{G}+\mathrm{C}$ group, clones 21 and 23 were closely related to Arthrobacter sp. and environmental (uncultured and unidentified) clones. One OTU from the Bacteroidetes group was related to Marinicola seohaensis $(<90 \%$ similarity).

The $\alpha$-proteobacteria was found to be the most predominant group on the MF membrane surface, which was in agreement with a previous study (Chen et al., 2004). 


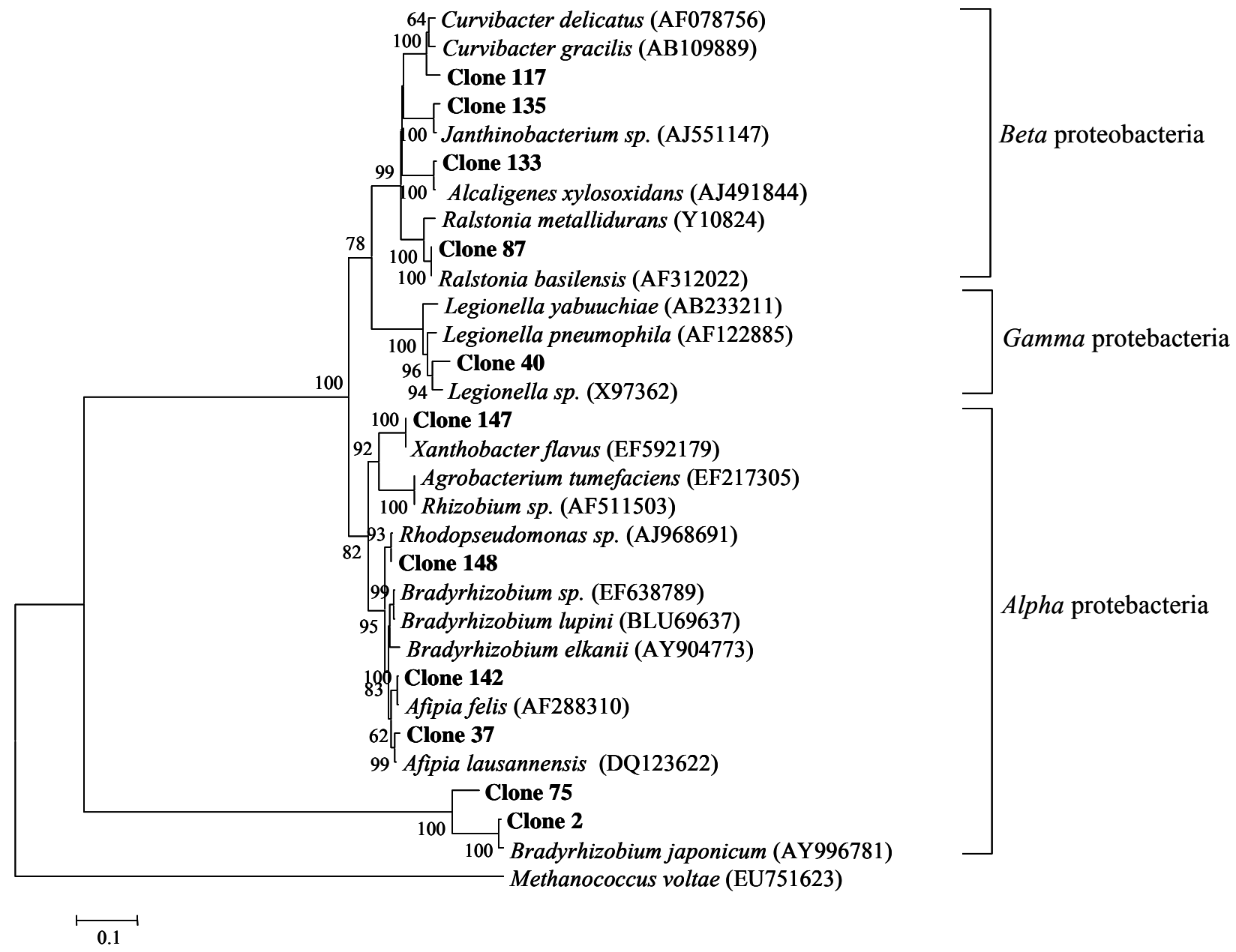

Figure 3. Phylogenetic tree of the proteobacteria based on 16S rDNA sequences obtained from cloning analyses of fouled MF membrane. Clones obtained from this study are shown in bold type. The tree was derived by performing the neighbor-joining method with a JukesCantor parameter in the MEGA version 3.1 programme. Bootstrap values greater than 50\% (1000 replicates) are shown. Methanococcus voltae EU751623 was used as the out-group to root the phylogram. The scale bar represents one substitution per ten nucleotides.

The $\alpha$-proteobacteria groups became the most dominant biofoulant under pressurized oligotrophic conditions. This result was expected since they are known to be well adapted to oligotrophic environments (Pinhassi and Hagström, 2000). The second largest $\beta$-proteobacteria group on the membrane surface is typically found in a freshwater environment, which is consistent with drinking water sources, like the Han River.

\section{Conclusions}

In this study, different classes and specific genes/species of bacteria existing in foulants on membranes used for drinking water treatment process were identified using 16S rRNA gene clone library method, in addition to separated chemical foulants characterization, including FTIR and 3-D fluorescence spectra analyses. $\alpha$-, $\beta$-, and $\gamma$-proteobacteria were found to be the dominant bacteria; however, specific bacte- ria found through genetic identification could not be directly compared to similar published results with membranes that were used for drinking water plants. Despite this, the finding that $\alpha$ - and $\beta$-proteobacteria were determined to be the most dominant bacteria in the fouled membrane is consistent with the fact that they are known to be mainly found in pressurized and oligotrophic conditions and relatively fresh water environments, respectively. The results provided in this study are expected to initiate future studies in the field of membrane biofouling.

Acknowledgements. This research was supported by a grant from the National Research Laboratory Program through the Korea Science and Engineering Foundation (NOM Lab: ROA-2007-20055-0).

Edited by: H. van Dijk 


\section{References}

Chen, C.-L., Liu, W.-T., Chong, M.-L., Wong, M.-T., Ong, S. L., Seah, H., and Ng, W. J.: Community structure of microbial biofilms associated with membrane-based water purification processes as revealed using a polyphasic approach, Appl. Microbiol. Biot., 63, 466-473, 2004.

Eichler, S., Christen, R., Höltje, C., Westphal, P., Bötel, J., Brettar, I., Mehling, A., and Höfle, M. G.: Composition and dynamics of bacterial community of a drinking water supply system as assessed by RNA- and DNA-based 16S rRNA gene fingerprinting, Appl. Environ. Microb., 72, 1858-1872, 2006.

Hall, T. A.: BioEdit: a user-friendly biological sequence alignment editor and analysis program for Windows 95/98/NT, Nucl. Acid. S., 41, 95-98, 1999.

Ivnitsky, H., Katz, I., Minz, D., Volvovic, G., Shimoni, E., Kesselman, E., Semiat, R., and Dosoretz, C. G.: Bacterial community composition and structure of biofilms developing on nanofiltration membranes applied to wastewater treatment, Water Res., 41, 3924-3925, 2007.

Kalmbach, S., Manz, W., Bendinger, B., and Szewzyk, U.: In situ probing reveals Aquabacterium Commune as a widespread and highly abundant bacterial species in drinking water biofilms, Water Res., 34(2), 575-581, 2000.

Kumar, S., Tamura, K., and Nei, M.: MEGA3: Integrated software for Molecular Evolutionary Genetics Analysis and sequence alignment, Brief. Bioinform., 5, 150-163, 2004.
Kwon, B., Lee, S., Cho, J., Ahn, H., Lee, D., and Shin, H. S.: Biodegradability, DBP formation, and membrane fouling potential of natural organic matter: Characterization and controllability, Environ. Sci. Technol., 39, 732-739, 2005.

Lee, N., Amy, G., and Croue, J.-P.: Low-pressure membrane (MF/UF) fouling associated with allochthonous versus autochthonous natural organic matter, Water Res., 40, 2357-2368, 2006.

Leenheer, J. A., Croue, J.-P., Benjamin, M., Korshin, G. V., Hwang, C. J., Bruchet, A., and Aiken, G. R.: Comprehensive isolation of natural organic matter from water for spectral characterizations and reactivity testing, ACS Sym. Ser., 76, 68-83, 2000.

Miura, Y., Hiraiwa, M. N., Ito, T., Itonaga, T., Watanabe, Y., and Okabe, S.: Bacterial community structures in MBRs treating municipal wastewater: relationship between community stability and reactor performance, Water Res., 41, 627-637, 2007.

Pang, C. M. and Liu, W.-T.: Community structure analysis of reverse osmosis membrane biofilms and the significnace of Rhizobiales bacteria in biofouling, Environ. Sci. Technol., 41, 47284734, 2007.

Pinhassi, J. and Hagström, Å.: Seasonal succession in marine bacterioplankton, Aquat. Microb. Ecol., 21, 245-256, 2000.

Thompson, J. D., Gibson, T. J., Plewniak, F., Jeanmougin, F., and Higgins, D. G.: The Clustal_X windows interface: flexible strategies for multiple sequence alignment aided by quality analysis tools, Nucleic Acids Res., 24, 4876-4882, 1997.

Weisburg, W. G., Barns, S. M., Pelletier, D. A., and Lane, D. J.: 16S ribosomal DNA amplification for phylogenetic study, J. Bacteriol., 173, 697-703, 1991. 